Part of Journal of Research of the National Bureau of Standards, Volume 18, January 1937

\title{
DETERIORATION OF CHROMIC ACID BATHS USED FOR ANODIC OXIDATION OF ALUMINUM ALLOYS
}

\author{
By R. W. Buzzard and J. H. Wilson
}

\section{ABSTRACT}

Commercial practice has shown that chromic acid baths for anodizing aluminum eventually fail. This failure, which had heretofore been attributed to other causes, has been shown to be caused by dissolved aluminum. The addition of chromic acid to the bath at regular intervals to maintain a constant $\mathrm{pH}$ is suggested as a means of improving bath control.

\section{CONTENTS}

I. Introduction

II. Procedure

III. Changes in bath composition

IV. Summary

\section{INTRODUCTION}

In the commercial operation of chromic acid baths for anodizing ${ }^{1}$ aluminum alloys, the baths eventually fail to produce good films. When inferior, films are first formed, the effectiveness of the solution may be temporarily restored by arbitrary additions of chromic acid, but a condition may be reached when further additions of chromic acid are without effect.

This report summarizes the results of a study made to determine the essential changes that occur in the continued operation of the chromic acid anodizing baths and the conditions that must be controlled to maintain such baths in effective operation.

\section{PROCEDURE}

Hexavalent and trivalent chromium, aluminum, iron, copper, chlorides, and sulphates were found in a spent bath that had been used at the Naval Aircraft Factory, Philadelphia, for anodizing aluminum alloys. Experiments with freshly prepared chromic acid baths, to which were added, singly, amounts of the above substances slightly in excess of those found in the spent bath, indicated that failure of the bath was caused by a decrease in the content of hexavalent chromium or an increase in that of aluminum. Iron and sulphates, even when added in considerable excess over the amounts found in the spent bath, did not adversely affect the bath performance.

\footnotetext{
1 The term "anodizing" is now commonly used in industry to refer to the production of a protective film on the surface of a metal, as aluminum, by making it the anode of a suitable electrolytic cell.
} 
Additions of chloride (which would not be present in normal bath operation) caused readily observable attack at both electrodes.

On the basis of these preliminary tests, the investigation was confined to a study of the changes in the concentration of the principal constituents; namely, hexavalent chromium, trivalent chromium, and aluminum.

The rate at which the chromic acid bath deteriorates when used was determined by anodizing sheets of $17 \mathrm{ST}$ aluminum alloy (dur-

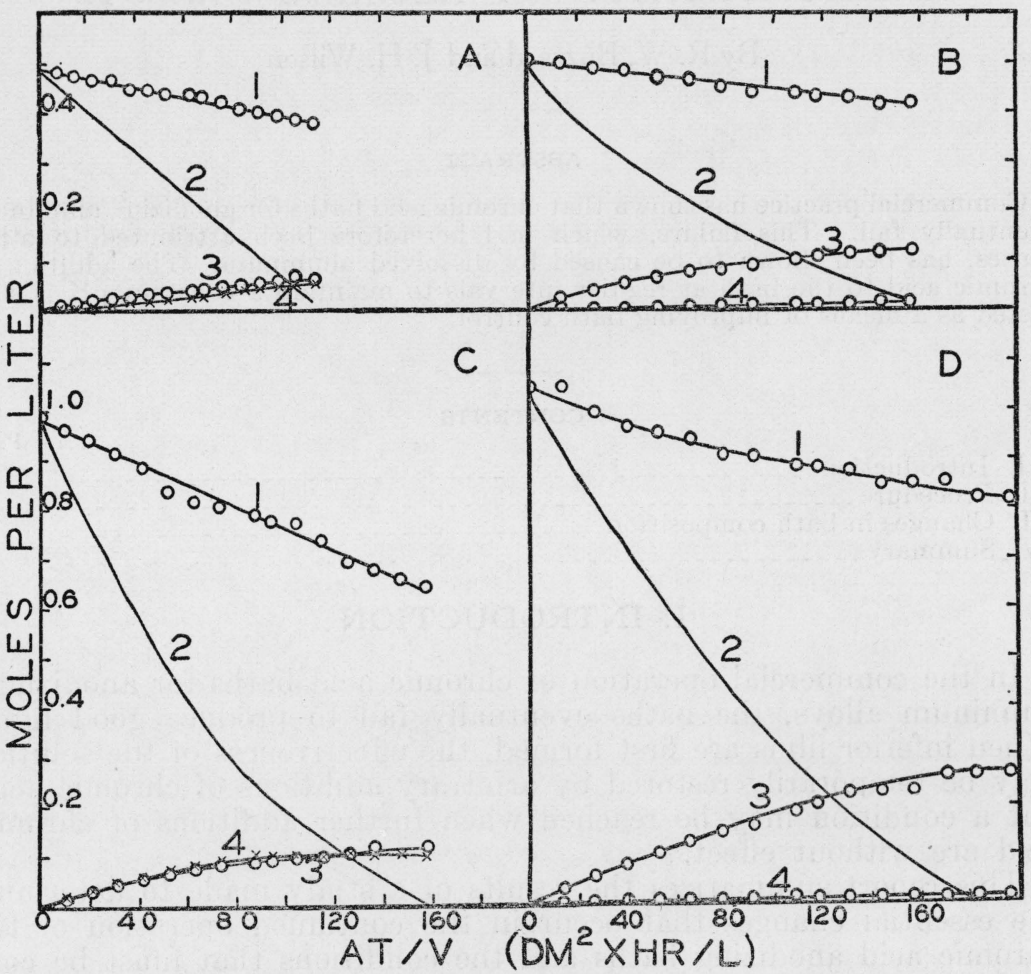

FIGURE 1.-Change in the concentration of principal constituents in anodizing baths with continued use.

A. 5 percent of chromic acid, large cathode.

$B$. 5 percent of chromic acid, small cathode.

C. 10 percent of chromic acid, large cathode.

D. 10 percent of chromic acid, small cathode.

1. Eexavalent chromium.

2. Free chromic acid.

3. Aluminum

4 Trivalent chromium.

alumin), each 10 by $10 \mathrm{~cm}$, in small glass battery jars varying in capacity from 4 to 7 liters. Iron cathodes were used, the areas of which were.varied in order to determine the effect of the ratio of anode to cathode area upon the rate of deterioration of the bath. Chromic acid solutions with concentrations of 3,5 , and 10 percent $(0.3,0.5$, and $1.0 M)$ were used. The anodizing was conducted at $40^{\circ}$ C. with a constant bath potential of 40 volts for periods of about 7 hours. The anodes were renewed hourly, and a sample of the solution was removed from the bath after each 25 hours of operation and analyzed. The baths were operated until a heavy sludge formed. 


\section{CHANGES IN BATH COMPOSITION}

In figure 1 is shown the rate of change of concentration of the constituents with continued use of the bath. The molar concentration, $M$, of each of the constituents of the solution is there plotted against the value of $A T / V$, in which $A$ is the anode area treated (in these experiments $A=2 \mathrm{dm}^{2}$ ), $T$ is the total time of the use of the bath (in hours), and $V$ is the volume of the bath (in liters).

The product of the total time the bath has been used and the average surface area treated is approximately proportional to the total quantity of electricity passed. In practical operation, the current density is not measured, but the operating conditions are maintained by bringing the voltage to the desired maximum, which is maintained the greater part of the anodizing period For practical purposes it may be assumed that the average current density was approximately constant during the greater part of the anodizing period. Allowance has been made for baths of different volume by dividing $A T$ by the volume of the bath. In effect, therefore, $A T / V$ is proportional to the number of ampere-hours per liter of solution.

In baths $A$ and $B$ (fig. 1 ) the chromic acid had an initial concentration of $0.5 M$ (5 percent) and in baths $C$ and $D$, twice this concentration. The cathode areas in baths $A$ and $C$ were 50 times those in $B$ and $D$.

It was found that the concentration of hexavalent chromium (curve 1, fig. 1) decreased, while that of aluminum and trivalent chromium (curves 3 and 4 , fig. 1 ) increased. In baths $B$ and $D$, with small cathode areas and correspondingly high cathode current densities, the increase of trivalent chromium was almost negligible. This difference is consistent with the fact that reduction of chromium from the hexavalent to the trivalent state is relatively greater at low than at high current densities.

The effective or available chromic acid has been expressed as free chromic acid by Haring and Barrows, ${ }^{2}$ in discussing the effective concentrations of chromic acid for chromium plating; and Kasper ${ }^{3}$ has shown that chromium dichromate, $\mathrm{Cr}_{2}\left(\mathrm{Cr}_{2} \mathrm{O}_{7}\right)_{3}$, is formed by the reduction of chromic acid. On the assumption that a similar compound of aluminum, $\mathrm{Al}_{2}\left(\mathrm{Cr}_{2} \mathrm{O}_{7}\right)_{3}$, is formed by the reaction between chromic acid and aluminum, the free chromic acid may be calculated as follows: free chromic acid, $(M)=\mathrm{Cr}^{\mathrm{VI}},(M)-3\left[\mathrm{Cr}^{\mathrm{III}},(M)+\mathrm{Al}\right.$, $(M)] . \quad(M=$ molar concentration. $)$

The changes in concentration of free chromic acid during the effective life of each bath are shown in curves 2 of figure 1 . In the freshly prepared baths the concentrations were the same as those of the hexavalent chromium. With continued operation of the bath the content of free chromic acid decreased steadily toward zero. Anodic films produced when the baths were in the latter condition had inferior corrosion resistance. It was also found that, as the baths became depleted in free chromic acid, a precipitate was formed, which finally collected as a heavy sludge in the bottom of the bath. This sludge was probably a basic chromate of chromium and aluminum. The more rapid increase in the aluminum concentration in baths $B$ and $D$, as

${ }^{2}$ H. E. Haring and W. P. Barrows, Electrodeposition of chromium from chromic acid baths. Tech. Pap. BS 21, 413 (1926-27) T346.

3 Charles Kasper, The structure of the chromic acid plating bath, the theory of chromium deposition. BS J. Research 9, 353 (1932) RP476. 
compared to that in baths $A$ and $C$, indicates that the presence of trivalent chromium in $A$ and $C$ retarded the dissolving of aluminum. The aluminum dissolves more rapidly with the higher initial concentration of chromic acid (fig. 2).

Numerous experiments indicate that successful anodization of aluminum depends upon the presence of free chromic acid. One very important difference between chromium dichromate and aluminum dichromate is that the trivalent chromium of chromium dichromate can be reoxidized at the anode to the hexavalent state, thereby releasing four moles of hexavalent chromium for each mole of trivalent chromium oxidized. This probably explains the fact that good films have been produced experimentally in anodizing baths composed essentially of chromium dichromate. On the other hand, this cannot be done with aluminum dichromate, and there is no effective method of removing aluminum from such baths. Hence, the aluminum permanently removes the hexavalent chromium from its free state.

In these anodizing solutions the favorable operating conditions vary with the initial concentration of chromic acid. A 3-percent $(0.3 M)$

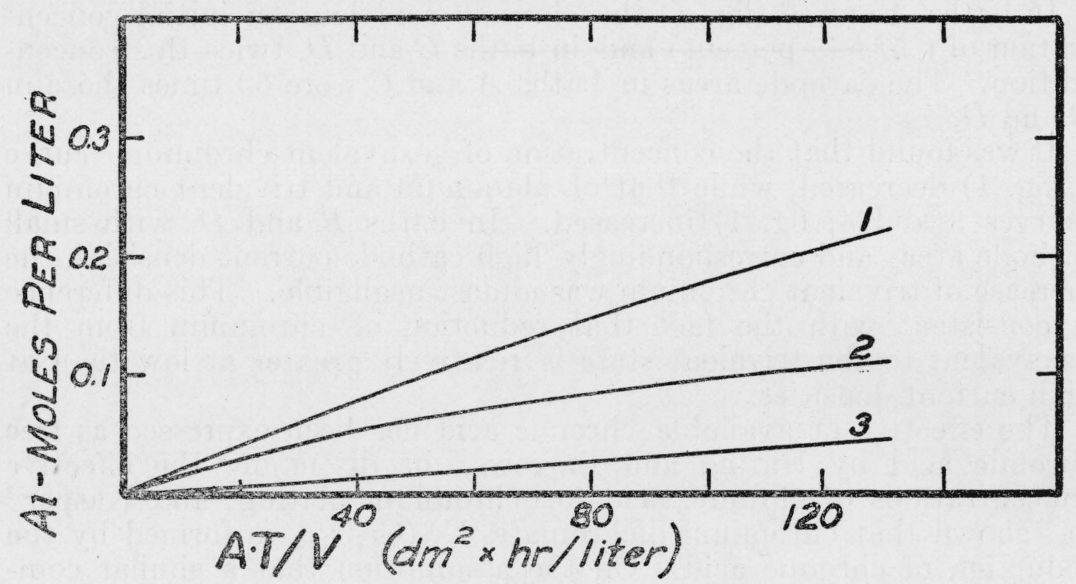

Figure 2.-Rate of solution of aluminum in chromic acid on anodizing.

1. 10-percent chromic acid bath.

2. 5-percent chromic acid bath.

3. 3-percent chromic acid bath.

chromic acid bath requires a definite voltage cycle to produce the best film, whereas 5 - and 10-percent $(0.5$ and $1.0 M)$ chromic acid baths anodize more successfully at constant voltage. Lower temperatures and voltages may be, used with the 10-percent chromic acid $(1.0 M)$ bath, and under proper operating conditions the time required for coating may be shortened. As the free chromic acid concentration of the solution decreases, the operating conditions must be altered to suit the new conditions of concentration, or else additions of chromic acid must be made to maintain the initial concentration of free acid.

Because free chromic acid is the determining factor in anodizing solutions, its concentration should be known and controlled. It is possible to maintain it at any desired concentration by making relatively simple determinations, as $\mathrm{pH}$ measurements. In figure 3 is shown the relation of the $\mathrm{pH}$ (determined by a glass electrode) to the free chromic acid concentration as the latter varies from that of a 
freshly prepared 10-percent bath to that of a completely broken down bath with no free chromic acid. It was found experimentally that by making frequent $\mathrm{pH}$ determinations and adding chromic acid in accordance with figure 3 to restore the original or any other desired $\mathrm{pH}$, the free chromic acid concentration of the bath can be maintained constant, and uniformly good films can be obtained.

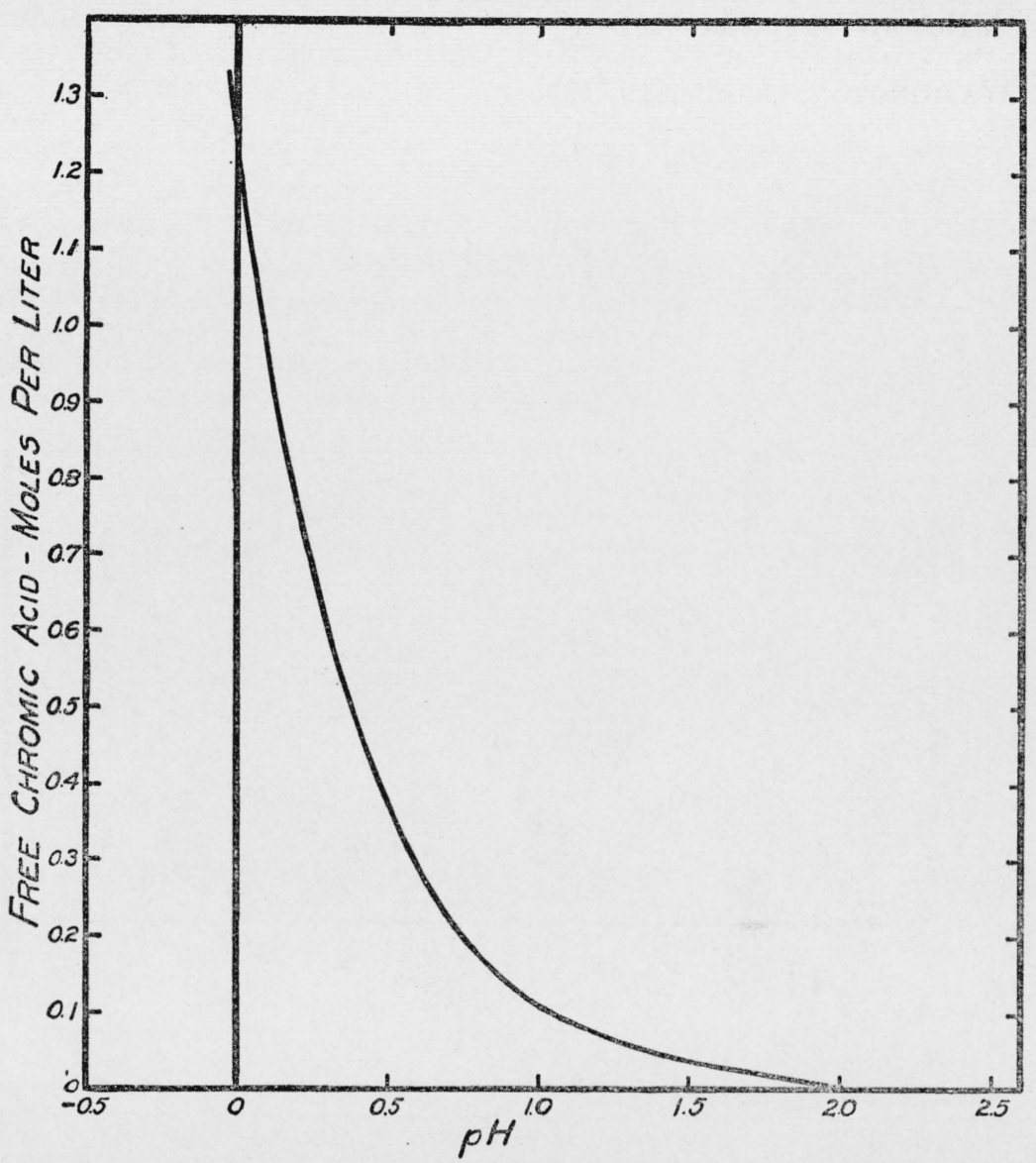

Figure 3.-Relation of $\mathrm{pH}$ to free chromic acid.

\section{SUMMARY}

1. Failure of anodizing baths as a result of use is caused principally by the neutralization of free chromic acid by aluminum.

2. The true criterion of the working condition of the bath is the concentration of free chromic acid. $\mathrm{pH}$ measurements with a glass electrode furnish a convenient means for determining and controlling the condition of the bath.

3. The useful life of an anodizing bath may be greatly prolonged by maintaining the solution at the required $\mathrm{pH}$. The free chromic acid content is maintained at the desired value by adding chromic acid to the bath in accordance with the $\mathrm{pH}$ values. 
4. Experience has shown that maintenance of the bath at a constant $\mathrm{pH}$ insures the obtaining of anodic oxide films that are very uniform in character.

The authors express their sincere thanks to Dr. William Blum and Dr. Richard M. Wick for their many helpful suggestions in connection with this investigation.

Washington, October 19, 1936. 